Journal of Thermal Engineering, Vol. 6, No. 6, pp. 297-312, April, 2020

Yildiz Technical University Press, Istanbul, Turkey

\title{
INVESTIGATION OF MODIFIED EJECTOR CYCLE ON RESIDENTIAL AIR CONDITIONER WITH ENVIRONMENTALLY BENIGN REFRIGERANT OF R290
}

\author{
Kasni Sumeru ${ }^{1, *}$, Mohamad Firdaus Sukri ${ }^{2,3}$, Pratikto Pratikto ${ }^{1}$, Apip Badarudin ${ }^{1}$
}

\begin{abstract}
This paper investigates a modified ejector cycle (MEC) to further enhance the COP improvement of residential air conditioner (A/C), as compared to the standard ejector cycle (SEC). This paper also presents numerical and experimental studies of the MEC. Numerical approach of MEC performances was evaluated by using SEC cycle that had been developed by many researchers. In the experimental study of MEC, three motive nozzle diameters of 0.9, 1.0 and $1.1 \mathrm{~mm}$ were utilized. In addition, environmentally friendly refrigerant of R290 (propane) was used as a working fluid. The modeling results of residential A/C with the cooling capacity of $2.5 \mathrm{~kW}$ showed higher COP improvements of MEC than SEC for all entrainment ratios of the ejector. There was no COP improvement for SEC at a low entrainment ratio, whereas there are always COP improvements for all entrainment ratios for MEC. In addition, the experimental results showed the highest COP improvement of $16.67 \%$ was achieved with the motive nozzle diameter of $1.1 \mathrm{~mm}$.
\end{abstract}

Keywords: Air Conditioner, Ejector, R290, Modified Ejector Cycle, Entrainment Ratio, COP Improvement

\section{INTRODUCTION}

Due to negative impact of CFCs (such as R11 and R12), HCFCs (such as R22 and R412b) and HFCs (such as R410A, R407C and R134a) as refrigerant on the environment, HCs (hydrocarbons) revive as working fluid in refrigeration and air conditioning systems. Early on, hydrocarbons have been used as working fluid in refrigeration and air conditioning system before synthetic refrigerants, namely CFCs, HCFCs and HFCs are introduced. Although, R22 is widely used as refrigerant in residential air conditioner (A/C), however due to its global warming effect and ozone depletion potentials, this refrigerant has to be replaced by environmental friendly refrigerants, such as HFCs and HCs. HFCs have zero ozone depletion potential, but they have negative effects on the global warming. As a result, these refrigerants are not considered as long term alternative replacement for R22. HCs have zero ozone depletion potential and very low greenhouse effect and therefore, they are the best long term alternative refrigerant for R22. In Southeast Asia countries such as Malaysia, Singapore and Indonesia, R290 is widely used to replace R22 in residential A/C. Many researchers have reported that the drop-in substitute from R22 to R290 in air conditioners enhance the performance of the system [1-3].

Besides replacing working refrigerant to improve the performance of the A/C [4], Sukri et. al. [5] also highlighted several other methods to enhance the performances of the $\mathrm{A} / \mathrm{C}$. Intensive investigations on those methods are now being carried out. Some of the methods are by adding nanoparticles into the refrigerant to increase the heat transfer process [6-8] and using ejector as an expansion device [9-24]. Recently, a method of transpiration cooling to enhance the heat transfer process was reported [23]. This method can also be investigated to improve the performance of condenser coil which later improves the overall performance of the $\mathrm{A} / \mathrm{C}$.

Typically, residential A/C uses capillary tube as expansion device. The use of this conventional expansion device generates energy losses during expansion process. The advantage of using ejector as an expansion device is huge as compared to other methods. It is because, this device does not require input energy to operate but has been proven in enhancing the performance of air-conditioning system. Fig. 1(a) and (b) show the schematic diagrams of

This paper was recommended for publication in revised form by Regional Editor Hafiz Muhammad Ali

${ }^{1}$ Department of Refrigeration \& Air Conditioning, PoliteknikNegeri Bandung Gegerkalong Hilir Ciwaruga, Bandung 40012, Indonesia

${ }^{2}$ Efficient Energy Technology (GrEET) Research Group, Universiti Teknikal Malaysia Melaka, Hang Tuah Jaya, Melaka, Malaysia

${ }^{3}$ Faculty of Mechanical Engineering, Universiti Teknikal Malaysia Melaka, Hang Tuah Jaya, 76100 Durian Tunggal, Melaka, Malaysia

${ }^{*}$ E-mail address: sumeru@polban.ac.id

Orcid id: 0000-0003-3052-9610, 0000-0002-0385-6897, 0000-0003-4335-2324, 0000-0001-6241-1532

Manuscript Received 23 April 2019, Accepted 27 August 2019 
standard cycle (SC) and standard ejector cycle (SEC), respectively. The SC and SEC represent the residential A/C using a capillary tube and an ejector as an expansion device, respectively.

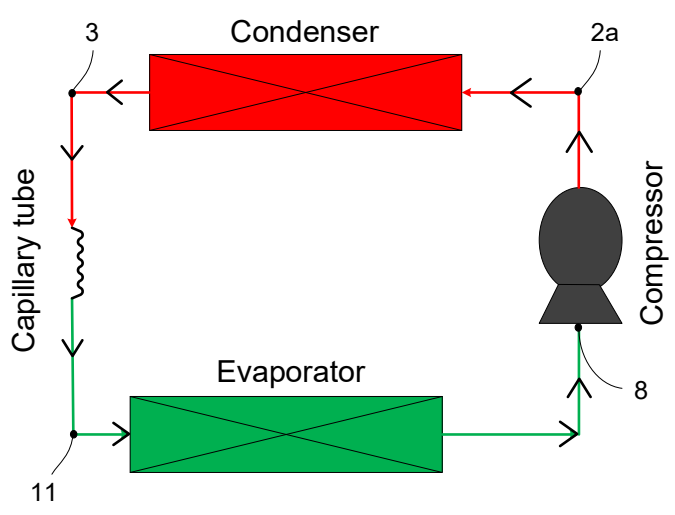

(a)

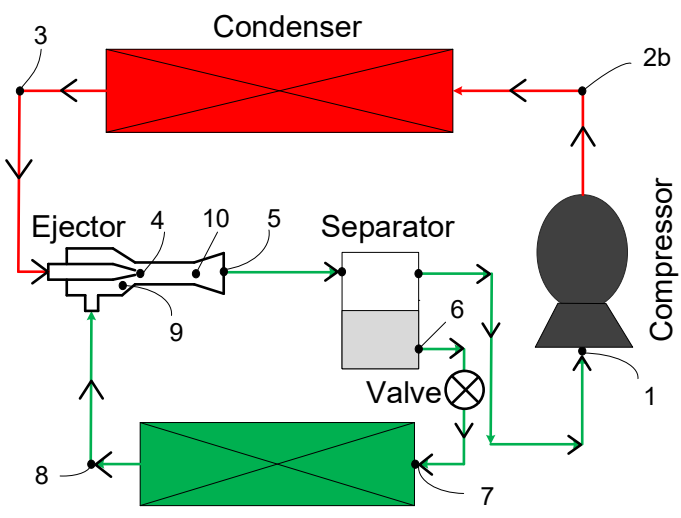

Evaporator

(b)

Figure 1. Schematic diagram: (a) Standard cycle, (b) Standard ejector cycle (SEC)

Kornhauser [9] was the first who investigated numerically in the vapor compression refrigeration cycle (VCRC) using an ejector as expansion device. He found COP improvement on eight refrigerants (i.e. R11, R12, R22, R113, R114, R500, R502 and R717) of refrigeration systems that operated with the evaporator and condenser temperatures of $-15^{\circ} \mathrm{C}$ and $30^{\circ} \mathrm{C}$, respectively. His investigation did not use R290 (propane) as working fluid because during that time, R290 was not yet considered as an alternative working fluid for VCRC. The investigation of the use of R290 as an alternative refrigerant for R22 started in 1990s. However, numerical investigation on the SEC using R290 as working fluid just started in 2010 by Sarkar [14] and 2013 by Sumeru et al. [15]. Sarkar [14] reported the COP improvement of SEC up to $17.9 \%$ when using $\mathrm{R} 290$ as refrigerant for condensing temperatures of $35^{\circ} \mathrm{C}$ to $55^{\circ} \mathrm{C}$. In addition, Sumeru et al. [15] investigated numerically on an air conditioner using SEC and found COP improvements of $4.94-32.90 \%$ for condensing temperatures from $40^{\circ} \mathrm{C}$ to $50^{\circ} \mathrm{C}$. Sarkar [14] and Sumeru et al. [15] concluded that $C O P$ improvement of SEC increased as the condensing temperature increased.

However, based on Fig. 1, it can be seen that at least, there are two drawbacks of SEC, namely: (i) not all refrigerant enters to the evaporator and as a result, it reduces cooling capacity; (ii) to generate COP improvement, it requires a high entrainment ratio ejector $(\omega)$. Detailed explanation of both disadvantages will be explained in the next section. In order to overcome these drawbacks, a new cycle was introduced by Sumeru et al. [20], called modified ejector cycle (MEC) as in Fig. 2.

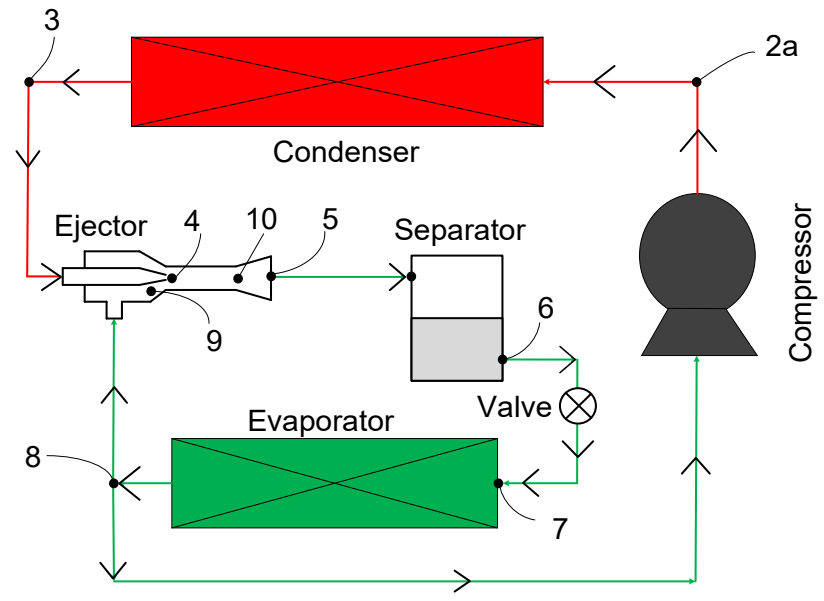

Figure 2. Schematic diagram of modified ejector cycle (MEC) 
Fig. 1(b) and Fig.2 show that the separator of SEC has one inlet and two outlets, whereas in the MEC, the separator has one inlet and only one outlet. Therefore, in the SEC, not all refrigerant flows through the evaporator and as a result it decreases the cooling capacity. Meanwhile, MEC has only one outlet and all refrigerant flows through the evaporator and as a result, the cooling capacity does not decrease. Due to energy balance, temperature of vapor refrigerant inside the separator reduces below its saturation vapor temperature and therefore vapor refrigerant in separator condenses inside the separator and becomes liquid refrigerant through a process called condensation heat transfer. As a result, separator releases heat to the surrounding air and reduction of enthalpy from point 5 to point 6 can be observed. Figure 3 shows the advantage of MEC over SEC depends on its dominant increase in cooling capacity (due to high refrigerant mass flow rate as compared to SEC, $\dot{m}_{r}>\left(\dot{m}_{r}-\dot{m}_{\text {cond }}\right)$ ), as opposed to a rise in compressor work from $\left(h_{2 b}-h_{1}\right)$ to $\left(h_{2 a}-h_{8}\right)$.

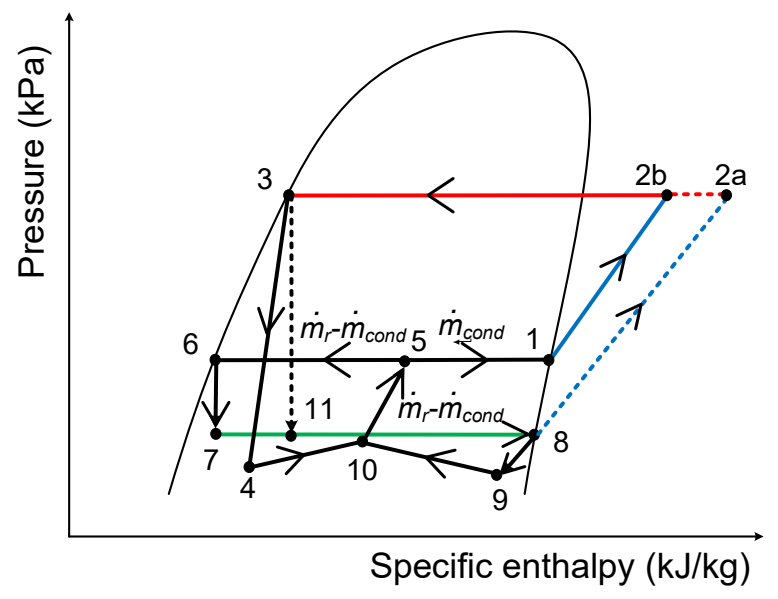

(a)

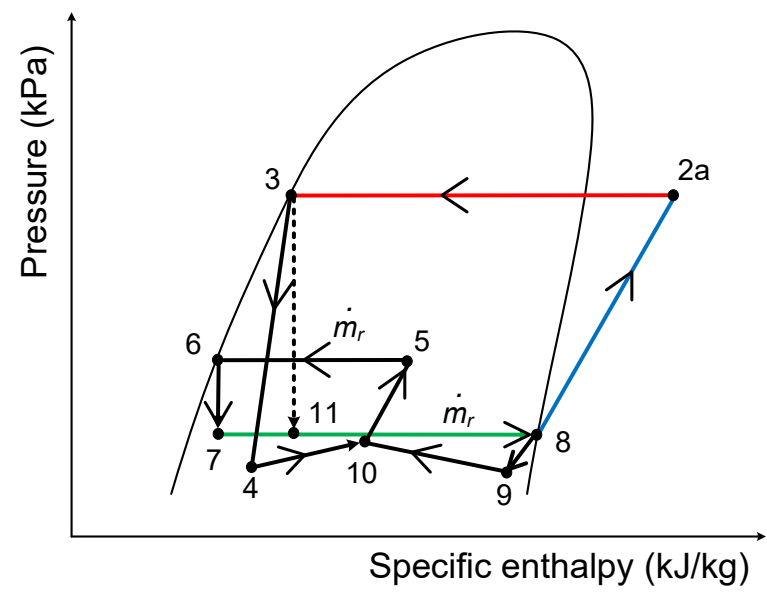

(b)

Figure 3. System cycle in $P$ - $h$ diagram: (a) Standard ejector cycle (SEC), (b) Modified ejector cycle (MEC)

The advantages of using MEC had been reported by Sumeru et al. [20]. Their experimental results showed that the MEC increased the $C O P$ of the residential $\mathrm{A} / \mathrm{C}$ of about $13.8 \%$ when the outdoor temperature of $40^{\circ} \mathrm{C}$. So far, the published studies on this research domain of MEC are very limited and according to author's knowledge, study of this cycle with benign refrigerant of R290 is yet to be conducted. Therefore, it is the aim of this study to further investigate the MEC using alternative future friendly refrigerant of R290 as a continuation from the previous work done by Sumeru et al. [20]. In the present study, numerical study of MEC using R290 as working fluid is conducted by varying the entrainment ratio and the condensing temperature, while the experimental study is carried out by varying the motive nozzle diameter.

\section{METHODOLOGY}

\section{Thermodynamic modeling}

The main parameter of the ejector is defined by entrainment ratio $(\omega)$, which is the ratio between the evaporator mass flow rate and the condenser mass flow rate, as shown in Eq. (1). The ejector is considered to perform better at higher entrainment ratio.

$$
\omega=\dot{m}_{\text {evap }} / \dot{m}_{\text {cond }}
$$


Numerical analysis on the SEC and MEC started from how to obtain the refrigerant properties at each point (points 1 to 10) as shown in Fig. 3(a) and (b). The procedure to determine the specific enthalpy at points 1 to 10 will be explained in this section.

The condition of specific enthalpy at point 1 was saturated vapor at $5^{\circ} \mathrm{C}$ (evaporating temperature), whereas the specific enthalpy at point $2 \mathrm{~b}$ was determined using equation as proposed by Brunin et al. [25], where:

$$
\eta_{\text {comp }}=0.874-0.0135 \frac{P_{\text {disc }}}{P_{\text {suct }}}
$$

According to Eq. (2), $\eta_{\text {comp }}, P_{\text {disc }}$ and $P_{\text {suct }}$ are the isentropic efficiency, discharge pressure and suction pressure of compressor, respectively. $P_{\text {disc }}$ and $P_{\text {suct }}$ were determined based on evaporating and condensing temperatures.

The specific enthalpy at point 3 was at saturated liquid condition, at condensing temperatures 0 $40^{\circ} \mathrm{C}$ and $50^{\circ} \mathrm{C}$. The specific enthalpy at point 4 was determined by using manipulated equation of energy conservation, as in Eq. (3). Based on Eq. (3), $\eta_{m n}$ is the isentropic efficiency of motive nozzle taken as 0.9 [14], while $h_{4, i s}$ is the specific enthalpy at point 4 when isentropic expansion process occurred from point 3 to 4 .

$$
h_{4}=h_{3}-\eta_{m n}\left(h_{3}-h_{4, i s}\right)
$$

The pressure at point 4 was determined by using Eq. (4), where $\rho, u, \omega$ and $a$ are density, velocity, entrainment ratio and cross-sectional area, respectively. Meanwhile, the specific enthalpy at point 10 (mixing area) was calculated by using Eq. (5).

$$
\begin{gathered}
\frac{P_{5}-P_{4}}{0.5 \rho_{4} u_{4}{ }^{2}}=2\left(\frac{a_{4}}{a_{5}}\right)-2(1-\omega)^{2}\left(\frac{\rho_{4}}{\rho_{5}}\right)\left(\frac{a_{4}}{a_{5}}\right)^{2} \\
h_{10}=\frac{1}{1+\omega}\left(h_{1}+\omega h_{10}\right)+\frac{u_{10}{ }^{2}}{2}
\end{gathered}
$$

The specific enthalpy at point 9 was determined as in Eq, (6), where $\eta_{s n}$ is the isentropic efficiency of suction nozzle with value of 0.9 [12]. $h_{9, \text { is }}$ is the specific enthalpy at point 9 when process from point 1 to 9 is isentropic.

$$
h_{9}=h_{1}-\eta_{s n}\left(h_{1}-h_{9, i s}\right)
$$

Next, energy conservation equation was applied to determine the specific enthalpy at point 5 (diffuser), and given as in Eq. (7). $\eta_{\text {dif }}$ is the diffuser isentropic efficiency with value of 0.8 [12]. Furthermore, the condition of specific enthalpy at point 6 and 8 were saturated liquid and saturated vapor respectively, while the specific enthalpy at point 7 was the same as in point 6 (isenthalpic process from point 6 to 7 ).

$$
h_{5}=h_{10}+\eta_{\text {dif }} \frac{u_{10}^{2}}{2}
$$

Procedure to determine the specific enthalpy at point $2 b$ was similar to the one used to obtain the specific enthalpy at point 2a by using Eq. (2). For steady state operation, the refrigerant quality at point 5 had to follow the Eq. (8) $[11-14,16]$, where:

$$
x_{5}=1 /(1+\omega)
$$


To apply these equations for determining the specific enthalpy refrigerant at each part of the ejector, the following assumptions were made $[14,15]$ :

i. Heat transfers only occurred in the evaporator, separator and condenser.

ii. Properties and velocities were constant over the cross section (one-dimensional).

iii. The refrigerant condition was in thermodynamic quasi-equilibrium.

iv. There was no pressure and wall friction drop along the evaporator and condenser.

v. The pressure at the exit of motive and suction nozzles at the entrance of the mixing-chamber were assumed to have the same pressure.

Upon determining the specific enthalpy at each point as shown in Fig. 3(a) and (b), the properties of the air conditioner can be calculated. There are three performance parameters of an air conditioner which will be discussed in the present study, namely the cooling capacity, compressor input power and COP improvement. Based on Fig. $3(\mathrm{a})$ and (b), the cooling capacity of SC, SEC and MEC were calculated using the following equations:

$$
\begin{gathered}
Q_{S C}=\dot{m}_{\text {evap }}\left(h_{8}-h_{11}\right) \\
Q_{S E C}=\dot{m}_{\text {evap }}\left(h_{8}-h_{7}\right)=\dot{m}_{\text {cond }} \cdot \omega\left(h_{8}-h_{7}\right) \\
Q_{M E C}=\dot{m}_{\text {evap }}\left(h_{8}-h_{7}\right)
\end{gathered}
$$

Meanwhile, the compressor input powers of SC, SEC and MEC were determined by:

$$
\begin{gathered}
W_{S C}=\dot{m}_{c o m p}\left(h_{2 a}-h_{8}\right) \\
W_{S E C}=\dot{m}_{c o m p}\left(h_{2 b}-h_{1}\right)=\frac{\dot{m}_{\text {evap }}}{\omega}\left(h_{2 b}-h_{1}\right) \\
W_{M E C}=\dot{m}_{c o m p}\left(h_{2 a}-h_{8}\right)
\end{gathered}
$$

Furthermore, the $C O P$ s of SC, SEC and MEC were:

$$
\begin{aligned}
& C O P_{S C}=\frac{Q_{\text {evap }}}{W_{\text {comp }}}=\frac{\dot{m}_{\text {evap }}\left(h_{8}-h_{11}\right)}{\dot{m}_{\text {comp }}\left(h_{2 a}-h_{8}\right)} \\
& C O P_{S E C}=\frac{Q_{\text {evap }}}{W_{\text {comp }}}=\frac{\dot{m}_{\text {evap }}\left(h_{8}-h_{7}\right)}{\dot{m}_{\text {comp }}\left(h_{2 b}-h_{1}\right)} \\
& C O P_{M E C}=\frac{Q_{\text {evap }}}{W_{\text {comp }}}=\frac{\dot{m}_{\text {evap }}\left(h_{8}-h_{7}\right)}{\dot{m}_{\text {comp }}\left(h_{2 a}-h_{8}\right)}
\end{aligned}
$$

The COP improvements of SEC and MEC over SC can be calculated by:

$$
C O P_{\text {imp } \_S E C}=\frac{\left(C_{-} P_{S E C}-C O P_{S C}\right)}{C O P_{S C}}
$$




$$
C O P_{\text {imp_MEC }}=\frac{\left(C_{-} P_{M E C}-C O P_{S C}\right)}{C O P_{S C}}
$$

The numerical algorithm explained in this sub-section can be illustrated using the flowchart as shown in Fig.4.

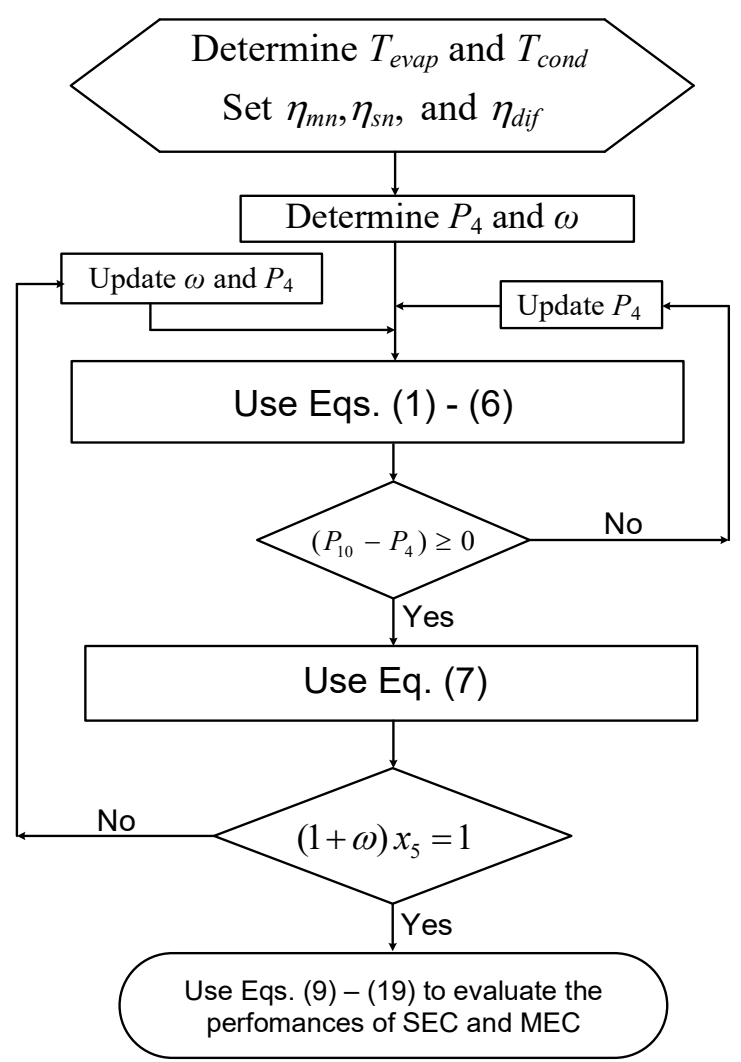

Figure 4. Flowchart for numerical approach to evaluate the performance of SEC and MEC

\section{Experimental setup and procedure}

Fig. 5 shows the schematic diagram of experimental setup. In this experiment, a split-type air conditioner that was originally using R22 as working fluid with cooling capacity of $2.5 \mathrm{~kW}$ was utilized. Before charging R290 to the system, R22 was evacuated. The charging mass of R 290 into system was $50 \%$ of mass of R22. The indoor and outdoor units were located separately. The indoor and outdoor temperatures were kept constant at $25^{\circ} \mathrm{C}$ and $34^{\circ} \mathrm{C}$, respectively. To obtain the cooling capacity generated by an evaporator, a ducting was utilized to measure the evaporator air outlet velocity. As shown in Fig. 5, evaporator air outlet velocity was measured at five different points and the average reading was used to determine the cooling capacity as accordance to Eq. (20). In this case, a pitot tube manometer was chosen for air velocity measurement.

Based on the numerical approach using flowchart as shown in Fig. 4, the diameters of motive nozzle and constant area of the ejector at evaporating and condensing temperatures of $5^{\circ} \mathrm{C}$ and $45^{\circ} \mathrm{C}$ were 1.03 and $2.14 \mathrm{~mm}$, respectively. As a result, in this experiment, one diameter below $1 \mathrm{~mm}$ and one above $1 \mathrm{~mm}$ were chosen. In short, three motive nozzle diameters of $0.9,1.0$ and $1.1 \mathrm{~mm}$ with constant diameter of $2.14 \mathrm{~mm}$ were used in the investigation. Fig. 6 shows the layout of an ejector in the experimental test rig and an ejector with three motive nozzle diameters of $0.9,1.0$ and $1.1 \mathrm{~mm}$. 
Three modes of experiment were carried out, namely SC, SEC and MEC. For each experimental mode, dry bulb $\left(T_{d b}\right)$ and wet bulb $\left(\mathrm{T}_{w b}\right)$ temperatures, refrigerant pressure $(P)$, air velocity $(u)$, electric current $(I)$ and voltage $(V)$ were measured to determine the cooling capacity $(Q)$, input power $(W)$ and $C O P$. The measurements were carried out at steady state condition. Each parameter was measured and repeated five times with 30 seconds of interval time for each measurement. The accuracies of each measuring instrument are shown in Table 1.

Table 1. The accuracies of measuring instruments

\begin{tabular}{|l|l|l|l|l|}
\hline No & Instruments & Measurements & Brand & Accuracy \\
\hline 1. & K-type thermocouple & Dry bulb temperature & APPA 55 II & $\pm 0.1^{\circ} \mathrm{C}$ \\
\hline 2. & K-type thermocouple & Wet bulb temperature & APPA 55 II & $\pm 0.1^{\circ} \mathrm{C}$ \\
\hline 3. & Clamp-on Ammeter & Electrical current & $\begin{array}{l}\text { KYORITSU-KEW } \\
\text { SNAP 2007A }\end{array}$ & $\pm 0.1 \mathrm{~A}$ \\
\hline 4. & Voltmeter & Electrical potential & $\begin{array}{l}\text { KYORITSU-KEW } \\
\text { SNAP 2007A }\end{array}$ & $\pm 1 \mathrm{~V}$ \\
\hline 5. & Pitot tube anemometer & Air velocity & Fluke 922 & $\pm 0.01 \mathrm{~m} / \mathrm{s}$ \\
\hline 6. & Refrigerant pressure gauge & Low Pressure & Refco & $\pm 0.1 \mathrm{bar}$ \\
\hline 7. & Refrigerant pressure gauge & High pressure & Refco & $\pm 0.5 \mathrm{bar}$ \\
\hline
\end{tabular}

The cooling capacity was determined using Eq. (20) with psychrometric chart as shown in Fig. 7, where $\rho$, $V, A, h_{R A}$ and $h_{S A}$ are density, velocity, cross-section area of ducting, enthalpies of room and supply airs, respectively. Furthermore, power and $C O P$ were calculated using Eqs. (21) and (22) respectively, where $\cos (\varphi)$ is power factor. In the present study, the power factor was 0.8 .

$$
\begin{gathered}
Q=\dot{m}\left(h_{R A}-h_{S A}\right)=\rho V A\left(h_{R A}-h_{S A}\right) \\
W=I \cdot V \cos (\varphi) \\
C O P=Q / W
\end{gathered}
$$

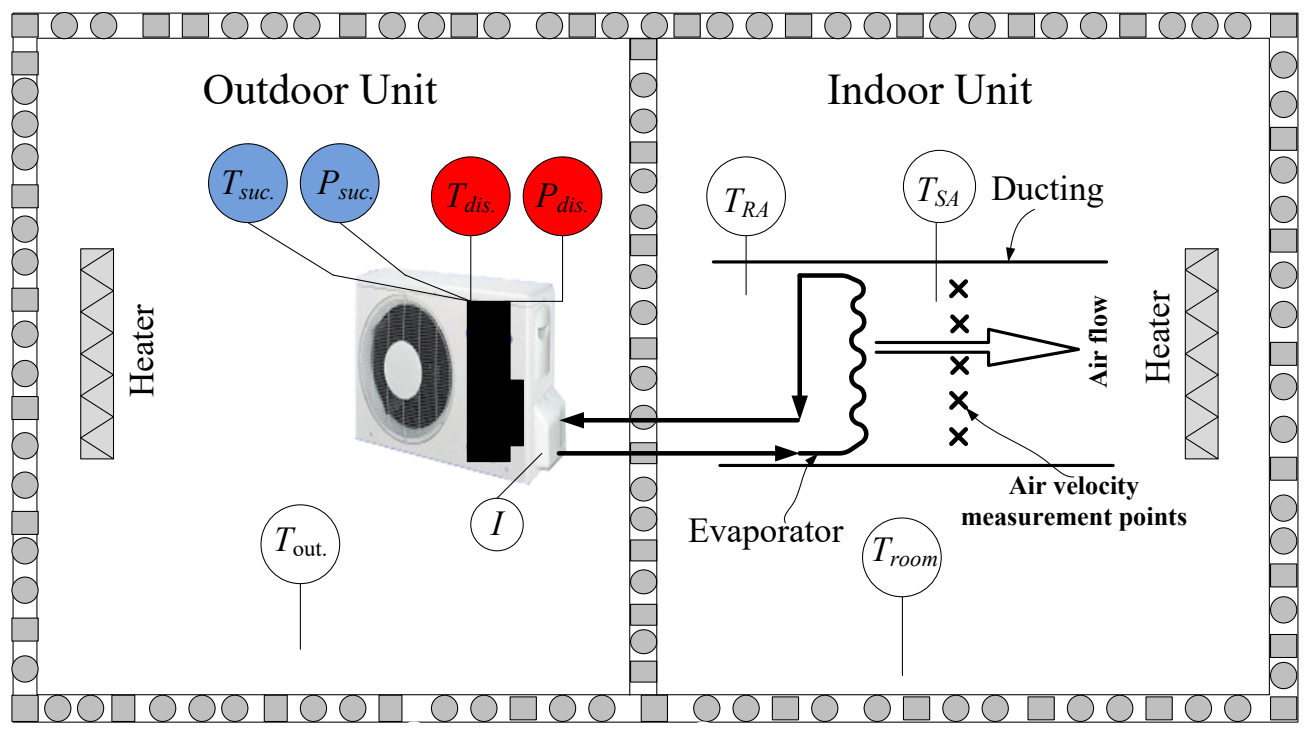

Figure 5. Schematic diagram of experimental setup 


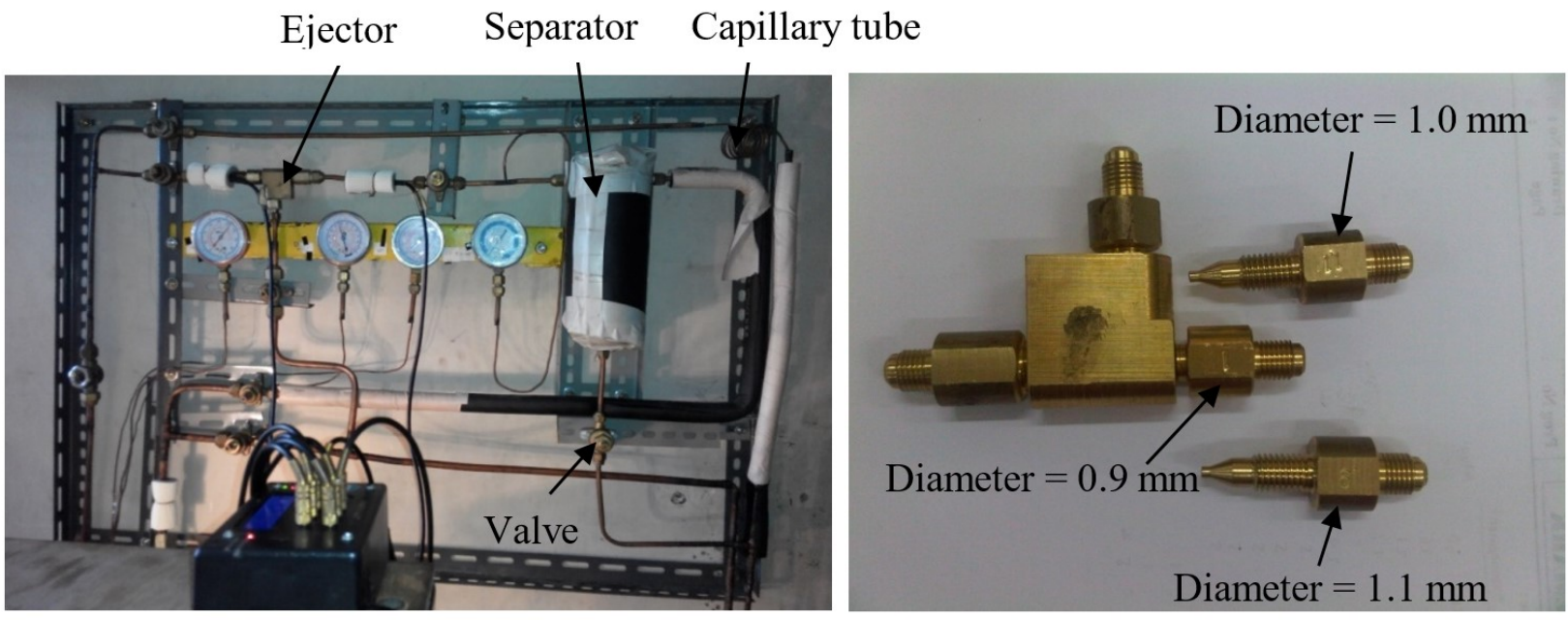

Figure 6. (a) The layout of an ejector in the experimental rig, (b) three motive nozzle diameters used in the experiments

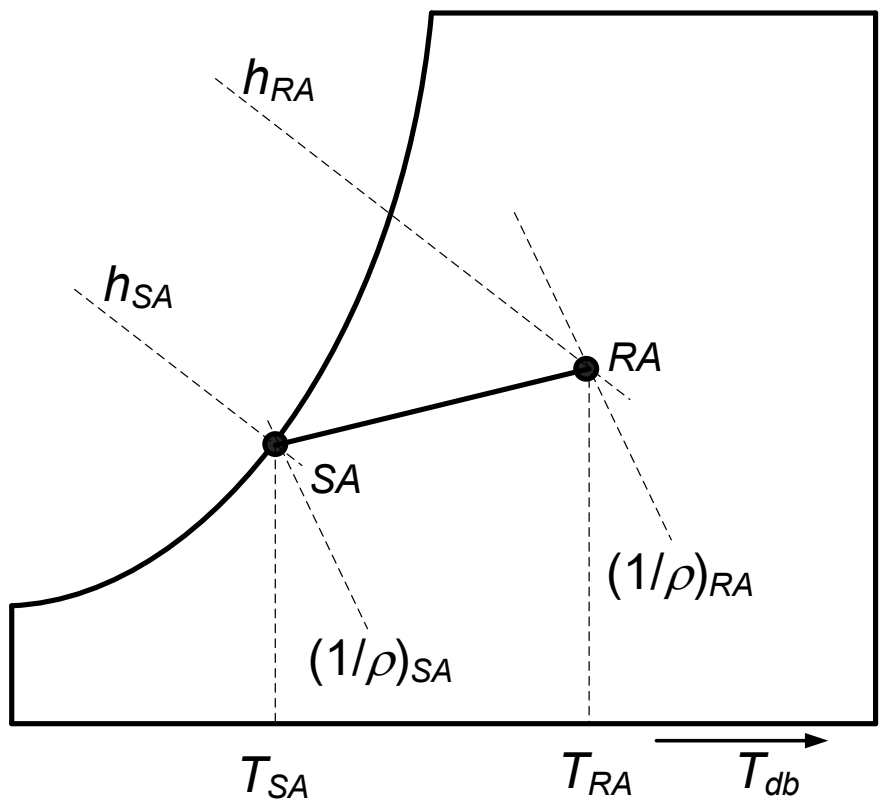

Figure 7. Air cooling process on the psychrometric chart to determine the cooling capacity

\section{RESULTS AND DISCUSSION}

A residential air conditioner $(\mathrm{A} / \mathrm{C})$ with evaporating temperature of $5^{\circ} \mathrm{C}$ using $\mathrm{R} 290$ refrigerant was used in the experiment. In the numerical approach, the effect of entrainment ratio on the cooling capacity, compressor power and $C O P$ improvement of SEC and MEC were investigated. In the numerical and experiment studies, the cooling capacities of $\mathrm{A} / \mathrm{C}$ were $2.5 \mathrm{~kW}$.

\section{Numerical results: effect of entrainment ratio on cooling capacity}

The cooling capacity of SEC and MEC were calculated using Eqs. (10) and (11), respectively. For the condensing temperature of $45^{\circ} \mathrm{C}$ and $50^{\circ} \mathrm{C}$, the specific enthalpy values of the equations were determined using Fig. 8 and Fig. 9. From the figures showed that the temperature at outlet diffuser $\left(T_{5}\right)$ increases with the increase of condensing temperature. At the condensing temperatures of $45^{\circ} \mathrm{C}$ and $50^{\circ} \mathrm{C}$, the temperatures of $\mathrm{T}_{5}$ are $7.7^{\circ} \mathrm{C}$ and 
$8.4^{\circ} \mathrm{C}$, respectively. The increase of $T_{5}$ increases $T_{6}$ and specific enthalpy at point 7 . It will decrease the cooling capacity due to decrease in enthalpy difference in the evaporator. At the condensing temperatures of $45^{\circ} \mathrm{C}$ and $50^{\circ} \mathrm{C}$, the specific enthalpy differences are $360.9 \mathrm{~kJ} / \mathrm{kg}$ and $359.0 \mathrm{~kJ} / \mathrm{kg}$, respectively.

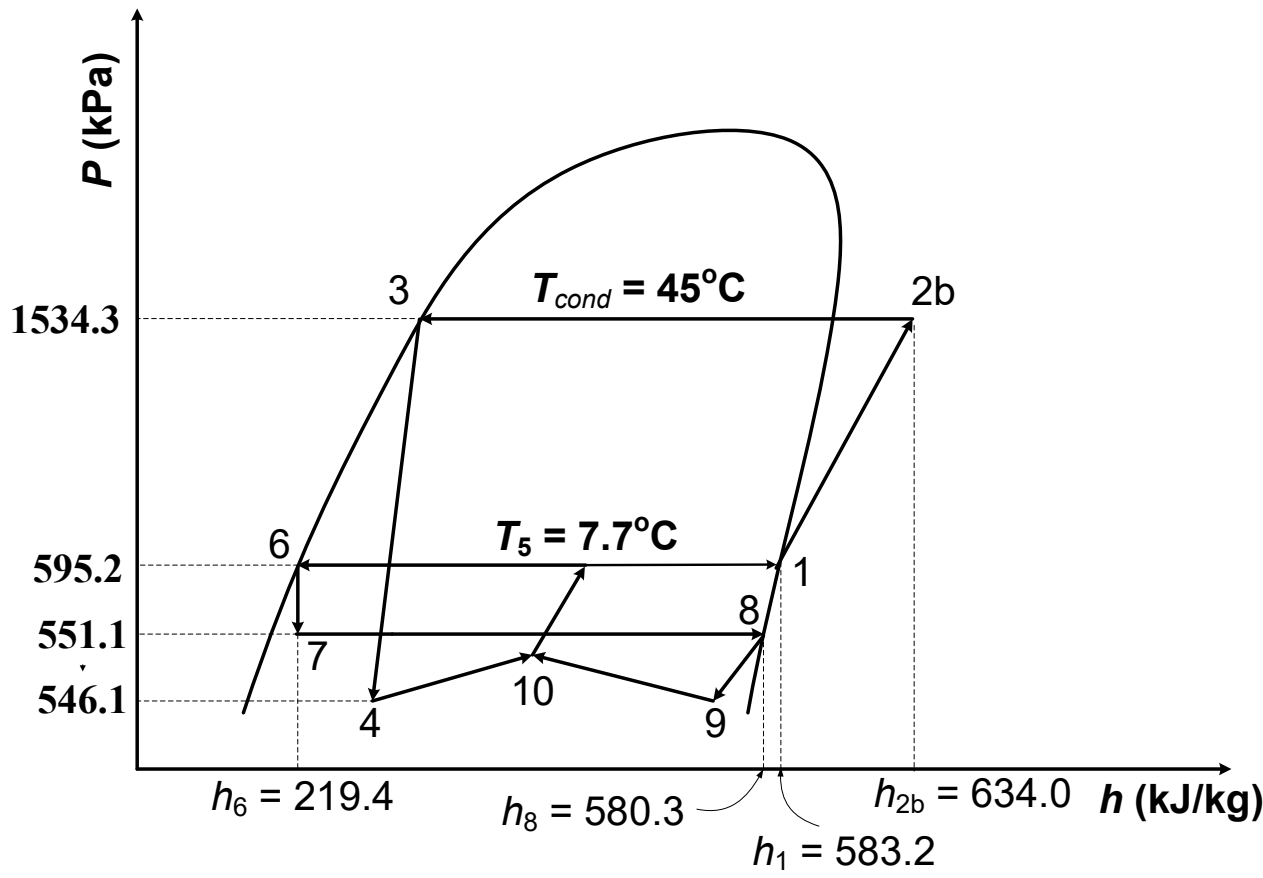

(a)

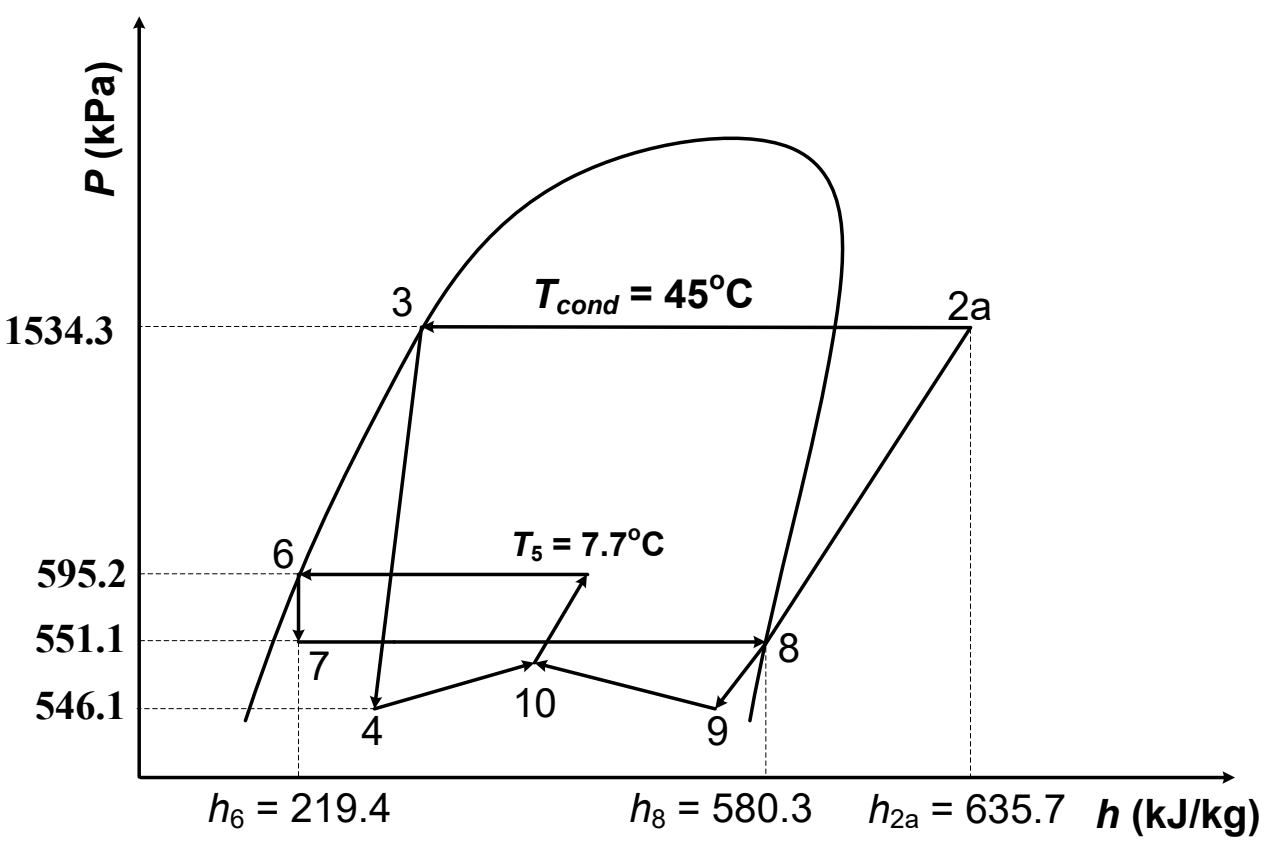

(b)

Figure 8. $P$ - $h$ diagram at the condensing temperature of $45^{\circ} \mathrm{C}\left(T_{\text {evap }}=5^{\circ} \mathrm{C}, \eta_{m n}=0.9, \eta_{s n}=0.9 \eta_{d i f}=0.8\right)$ : (a) SEC, (b) MEC 
Fig. 10 shows the cooling capacities of SEC and MEC, where the dash and continuous lines represent the SEC and MEC respectively. It can be seen from Fig. 10 that the cooling capacity of MEC is always higher than SEC for all entrainment ratios. The figure shows that the increase in condensing temperature from $45^{\circ} \mathrm{C}$ to $50^{\circ} \mathrm{C}$ slightly decreases the cooling capacity of SEC and MEC. Consequently, the lines are nearly coincident with the increase of entrainment ratio. In this study, the cooling capacity of SC at the condensing temperature of $45^{\circ} \mathrm{C}$ is $2.5 \mathrm{~kW}$. In the numerical approach, the cooling capacities of MEC are higher, which are $2.777 \mathrm{~kW}$ and $2.770 \mathrm{~kW}$ for the condensing temperatures of $45^{\circ} \mathrm{C}$ and $50^{\circ} \mathrm{C}$, respectively. In addition, the figure shows that the MEC cooling capacity is independent of the entrainment ratio, but SEC cooling capacity is dependent on the entrainment ratio. In other words, the cooling capacity of MEC is not influenced by entrainment ratio of the ejector. Because the cooling capacity is the most important performance of the $\mathrm{A} / \mathrm{C}$, higher cooling capacity of $\mathrm{MEC}$ as compared to SC indicates that the use of $\mathrm{MEC}$ in an air conditioning is promising.

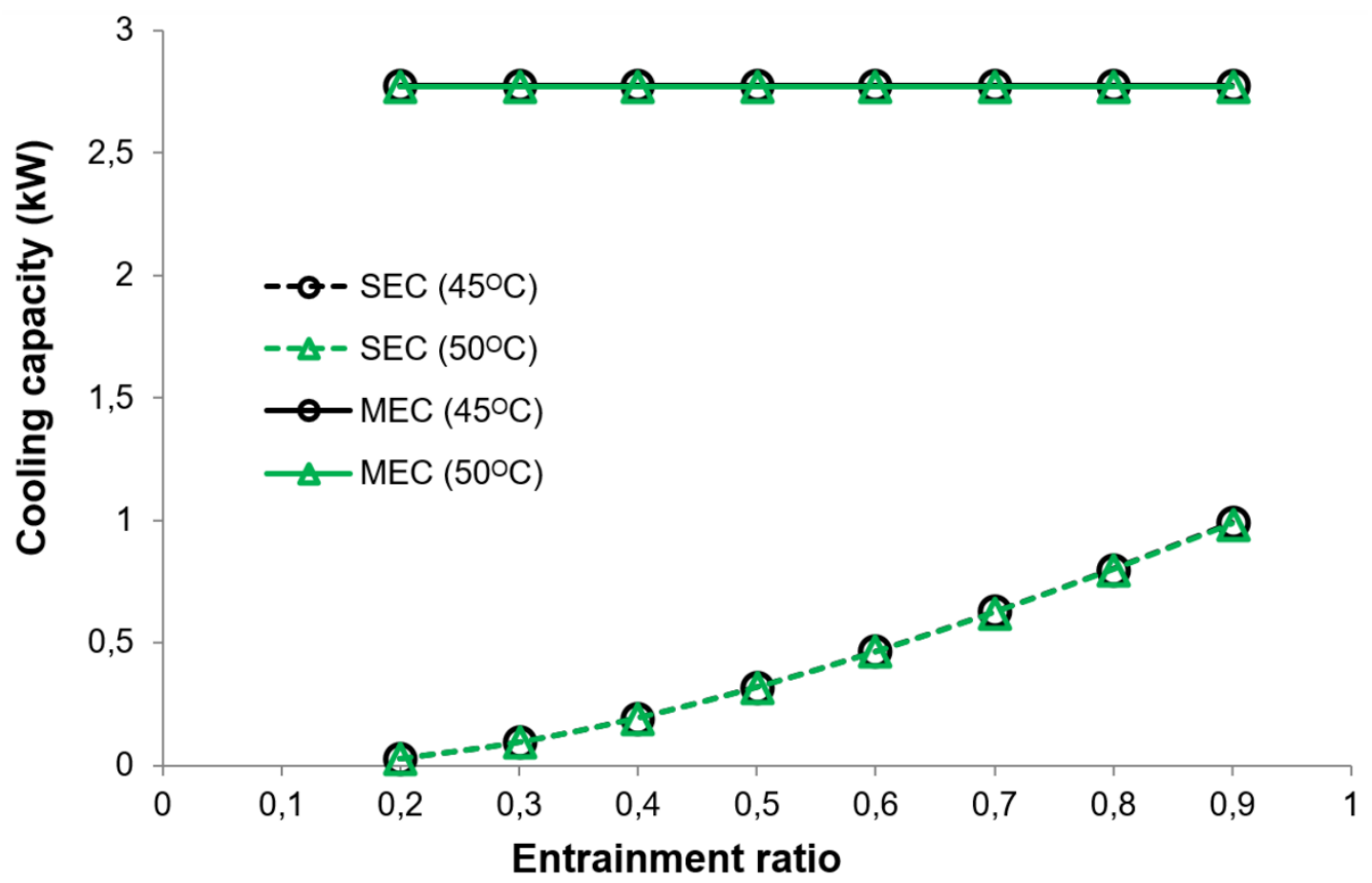

Figure 10. Comparison of cooling capacity between SEC and MEC for different condensing temperatures and various entrainment ratios

\section{Numerical results: effect of entrainment ratio on compressor power}

The compressor power is the power consumed by the compressor and calculated by using Eqs. (13) and (14) for SEC and MEC, respectively. From the equations, it can be seen that the input power of SEC is always lower than MEC because the entrainment ratio of the ejector is always lower than unity at the same condensing temperature, as shown in Fig. 11. The figure shows that the increase of entrainment ratio decreases the input power of SEC and MEC. By increasing the condensing temperature also significantly increases the input power.

The low value of input power for SEC as compared to MEC is because of the lower specific enthalpy difference of SEC than MEC, which are $50.8 \mathrm{~kJ} / \mathrm{kg}$ and $55.4 \mathrm{~kJ} / \mathrm{kg}$ at the condensing temperature of $45^{\circ} \mathrm{C}$ and 55.9 $\mathrm{kJ} / \mathrm{kg}$ and $62.1 \mathrm{~kJ} / \mathrm{kg}$ at the condensing temperature of $50^{\circ} \mathrm{C}$ for the SEC and MEC, respectively. The low input power of SEC does not indicate that SEC is better than MEC. It is because, although SEC requires lower input power, it also produces lower cooling capacity than MEC, as explained in the previous discussion. For the purpose of comparing both systems, the coefficient of performance $(C O P)$ is utilized to justify which of the system is better. 


\section{Numerical results: effect of entrainment ratio on COP improvement}

As mentioned in the previous section, $C O P$ is defined by Eq. (15). This parameter is mostly used as an indicator of A/C performance. Using Eqs. (18) and (19), The COP improvements of SEC and MEC are shown in Fig. 12. The figure shows that $C O P$ improvements of SEC are negative for a low entrainment ratio. The COP improvements become positive when the entrainment ratios are higher than 0.78 and 0.81 for the condensing temperatures of $45^{\circ} \mathrm{C}$ and $50^{\circ} \mathrm{C}$. This means that the $C O P$ improvements of SEC are zero if the entrainment ratios are 0.78 and 0.81 for the condensing temperatures of $40^{\circ} \mathrm{C}$ and $50^{\circ} \mathrm{C}$, respectively. Meanwhile, the $C O P$ improvements of MEC are always positive for all entrainment ratios. In other words, to generate $C O P$ improvement in SEC, an ejector with high entrainment ratio must be used. In the MEC, COP improvement can still be produced by using an ejector with low entrainment ratio, although high entrainment ratio will generate higher $C O P$ improvement.

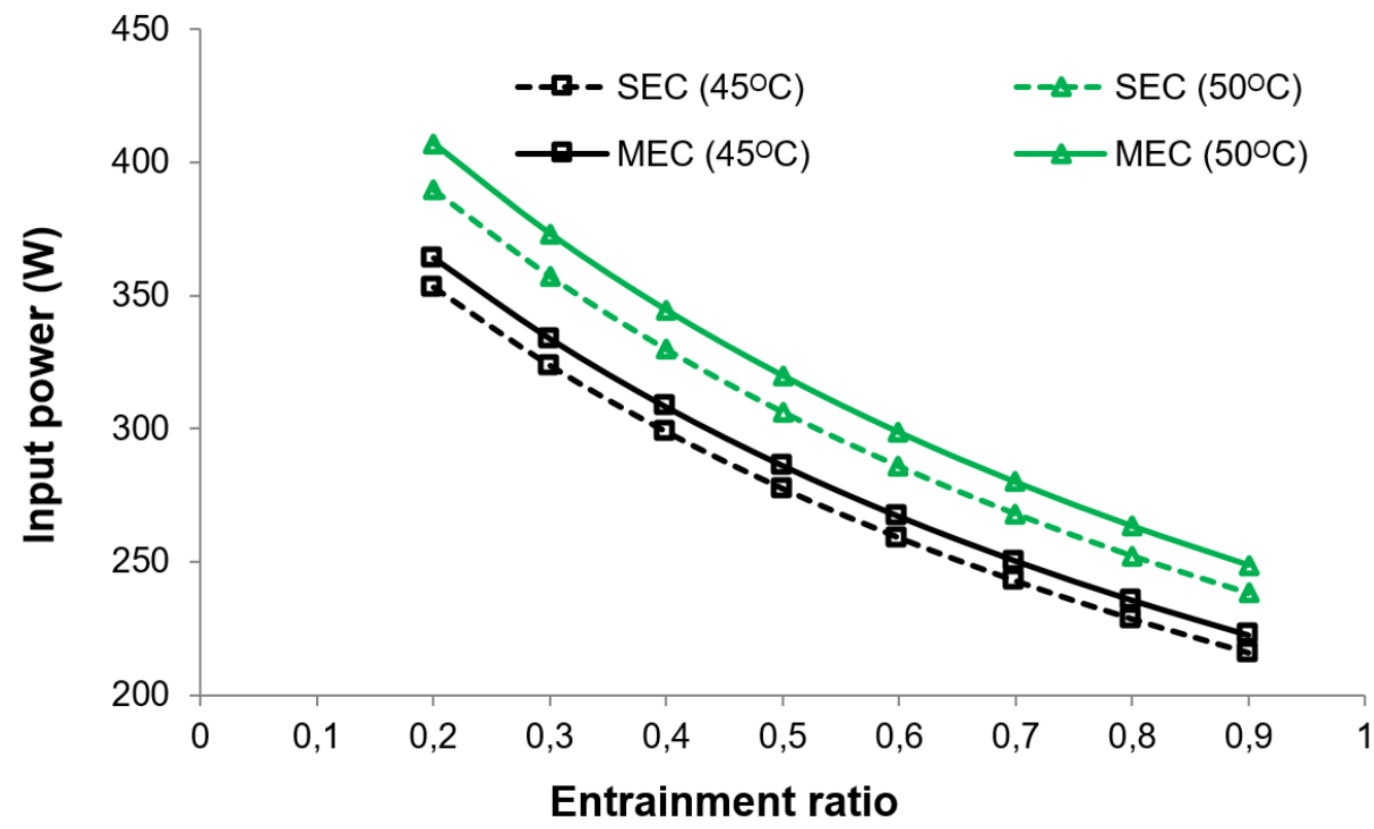

Figure 11. Comparison of input power between SEC and MEC for different condensing temperatures and various entrainment ratios

Fig. 12 shows that the COP improvements of MEC achieve 77.76 to $181.45 \%$ and 89.18 to $199.53 \%$ at the condensing temperatures of $45^{\circ} \mathrm{C}$ and $50^{\circ} \mathrm{C}$, respectively for entrainment ratio from 0.2 to 0.9 . Meanwhile, the $C O P$ improvements of SEC achieve -93.89 to $24.70 \%$ and -93.41 to $33.42 \%$ at the condensing temperatures of $45^{\circ} \mathrm{C}$ and $50^{\circ} \mathrm{C}$, respectively for entrainment ratio from 0.2 to 0.9 . This indicates that the use of ejector as an expansion device for MEC produces higher COP improvement than SEC.

Sumeru et al. [20] had conducted modeling and experimentation of MEC on a split-type A/C using R22 as working fluid. Their experimental results reported that the MEC improved the COP by 4.32, 11.30 and $18.29 \%$ for the ambient temperatures of 30,35 and $40^{\circ} \mathrm{C}$, respectively. These results indicate that the MEC is able to be applied in the $\mathrm{A} / \mathrm{C}$ and generates $C O P$ improvement.

\section{Experimental results}

There are several parameters to indicate the performance of $\mathrm{A} / \mathrm{C}$. In this paper, three parameters are reported, namely the cooling capacity, input power and COP. As mentioned in the previous section, the optimum diameter of the motive nozzle was $1.03 \mathrm{~mm}$. Based on the experimental results using three diameters; the diameter of $1.1 \mathrm{~mm}$ gave the highest $C O P$ improvement, as shown in Fig. 13. 


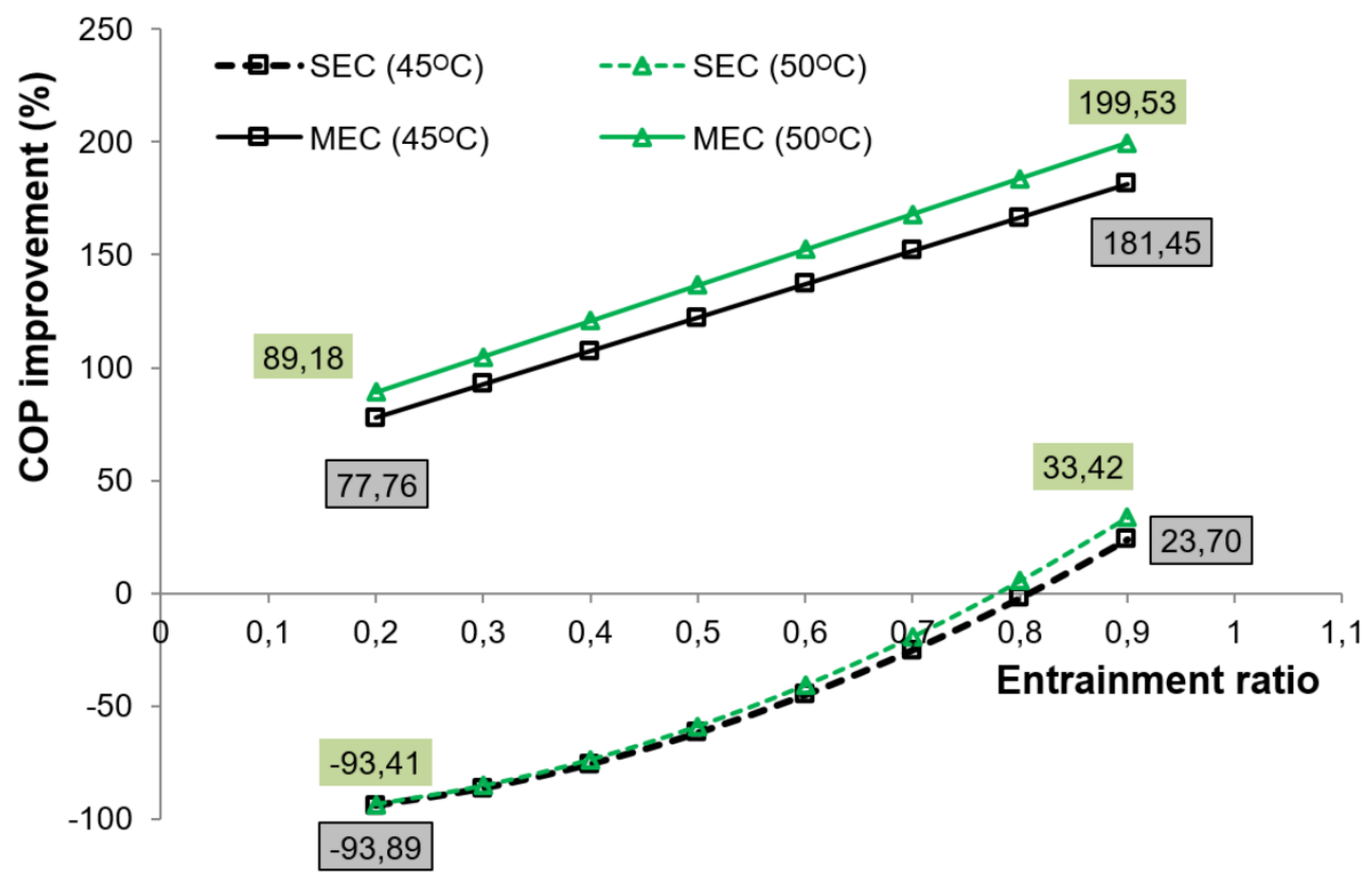

Figure 12. Comparison of $C O P$ improvement between SEC and MEC for condensing temperatures and various entrainment ratios

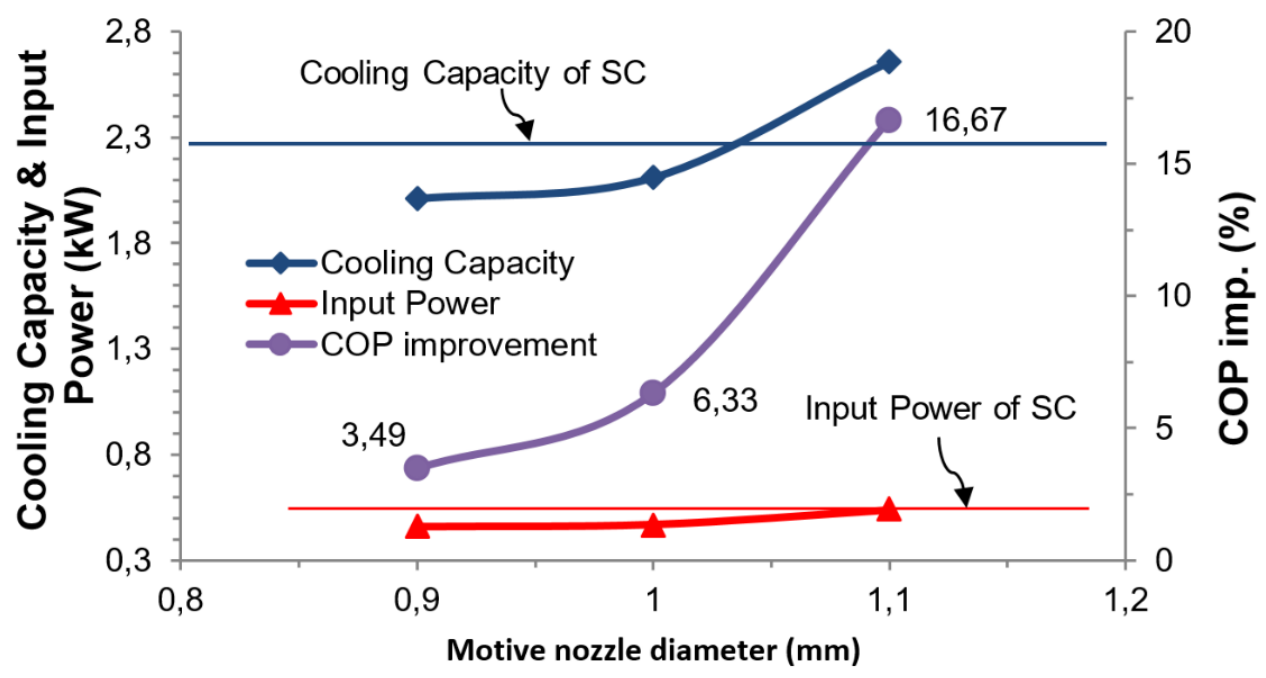

Figure 13. The comparison of the cooling capacity, input power and $C O P$ improvement for three motive nozzle diameters of MEC

Fig. 13 shows the experimental results using three motive nozzle diameters. The cooling capacity was calculated using Eq. (20) by plotting supply and room air conditions in the psychrometric chart as shown in Fig. 7. Furthermore, the input power, $C O P$ and $C O P$ improvement were determined using Eqs. (21), (22) and (19), respectively. The figure depicts that the cooling capacities of MEC using motive nozzle diameters of 0.9 and $1.0 \mathrm{~mm}$ 
are below the SC. The cooling capacity of SC $(2.28 \mathrm{k} \mathrm{W})$ is higher than that of MEC using 0.9 and $1.0 \mathrm{~mm}$ motive nozzle diameters, i.e., 2.01 and $2.11 \mathrm{~kW}$, respectively. Meanwhile, the cooling capacity of MEC uses $1.1 \mathrm{~mm}$ motive nozzle diameter is above SC, which is $2.66 \mathrm{~kW}$. Although the cooling capacities of MEC with 0.9 and 1.0 diameters are below SC, the $C O P$ of those diameters are above the $\mathrm{SC}$ because the input powers of both diameters are below SC. The input power of SC is $0.54 \mathrm{~kW}$, whereas the input powers of MEC with 0.9 and $1.0 \mathrm{~mm}$ are 0.46 and 0.47 $\mathrm{kW}$. As a result, the $C O P$ improvements of 0.9 and $1.0 \mathrm{~mm}$ are positive although they are not significant, that is only 3.49 and $6.22 \%$, respectively. Meanwhile, the input power of MEC with $1.1 \mathrm{~mm}$ diameter is $0.54 \mathrm{~kW}$, which is the same as SC. However, because the cooling capacity of MEC with $1.1 \mathrm{~mm}$ diameter is significantly higher than SC, the COP improvement of MEC with $1.1 \mathrm{~mm}$ diameter is also significant, with the value of $16.67 \%$. A smaller COP improvement as compared to the numerical result is due to lower entrainment ratio of ejector used during experimental work.

Table 2 shows the $C O P$ improvement comparison between the experimental result and other studies. The table depicts that the $C O P$ improvement in this investigation is higher than the others, with the exception of experimental result that was carried out by Taslimitaleghani et al. [26]. The COP improvement in their experimental result was $23 \%$. It can be understood because their experiment used $\mathrm{CO}_{2}$ as working fluid [27], where the compression ratio of $\mathrm{CO}_{2}$ is much higher than $\mathrm{R} 290$. As a result, the energy recovery potential during expansion using $\mathrm{CO}_{2}$ is also much higher than $\mathrm{R} 290$. Consequently, the potential of $C O P$ improvement using $\mathrm{CO}_{2}$ is higher than that of R290.

Table 2. The experimental results on the SEC and MEC by the investigators

\begin{tabular}{|l|c|c|c|c|}
\hline Authors & Year & COP & Working fluid & Cycle \\
\hline Harrell and Kornhauser [28] & 1995 & $3.9-7.6 \%$ & $\mathrm{R} 134 \mathrm{a}$ & SEC \\
\hline Menegay \& Kornhauser [29] & 1996 & $3.2-3.8 \%$ & $\mathrm{R} 12$ & SEC \\
\hline Deng et al. [27] & 2007 & $22 \%$ & $\mathrm{CO}_{2}$ & SEC \\
\hline Elbel \& Hrnjak [30] & 2008 & $7 \%$ & $\mathrm{CO}_{2}$ & SEC \\
\hline Elbel [31] & 2011 & $7 \%$ & $\mathrm{CO}_{2}$ & SEC \\
\hline Lucas \& Koehler [32] & 2012 & $17 \%$ & $\mathrm{CO}_{2}$ & SEC \\
Sumeru et al. [20] & 2014 & $4.17-13.78 \%$ & $\mathrm{R}_{2} 2$ & MEC \\
Bilir et al. [18] & 2015 & $7.34-12.87 \%$ & $\mathrm{R} 134 a$ & SEC \\
\hline Haida et al. [33] & 2016 & $7 \%$ & $\mathrm{CO}_{2}$ & SEC \\
\hline Palacz et al. [34] & 2017 & $6 \%$ & $\mathrm{CO}_{2}$ & SEC \\
\hline Taslimitaleghani et al. [26] & 2018 & $35 \%$ & $\mathrm{R} 290$ & SEC \\
\hline
\end{tabular}

The disadvantage of using MEC as compared to SEC is how to control the superheating degree of evaporator in order to keep the state of refrigerant at point 8 (refer to Fig. 2) in vapor phase and to ensure the safety of the compressor. In this study, the superheating is ensured by adjusting the valve between point 6 and 7 (refer to Fig. 2) manually. In the future, it is quite possible to replace this manual valve with an electronic valve, so that the degree of valve opening is controlled automatically with good precision through temperature feedback sent by a temperature sensor located at point 8 .

\section{Experimental uncertainty analysis}

The uncertainties of parameters in the present study were evaluated using the experimental standard deviation of the measured values [20]. The relative standard uncertainty of input power, cooling capacity and COP were calculated by Eqs. (23), (24) and (25). $\bar{W}_{\text {input }}, \bar{Q}_{\text {evap }}$ and $\overline{C O P}$ are the average values of input power, cooling capacity and coefficient of performance, respectively. As explained in the previous section, each parameter was measured five times. The experimental uncertainties of input power, cooling capacity and coefficient of performance for three motive nozzle diameters were less than $0.83 \%, 0.97 \%$ and $1.26 \%$, respectively. 


$$
\begin{gathered}
U\left(W_{\text {input }}\right)=\sqrt{\frac{\sum_{i=0}^{n}\left(W_{\text {input }}-\bar{W}_{\text {input }}\right)^{2}}{n \cdot(n-1) \bar{W}_{\text {input }}^{2}}} \\
U\left(Q_{\text {evap }}\right)=\sqrt{\frac{\sum_{i=0}^{n}\left(Q_{\text {evap }}-\bar{Q}_{\text {evap }}\right)^{2}}{n \cdot(n-1) \bar{Q}_{\text {evap }}^{2}}} \\
U(C O P)=\sqrt{\frac{\sum_{i=0}^{n}(C O P-\overline{C O P})^{2}}{n \cdot(n-1) \overline{C O P}^{2}}}
\end{gathered}
$$

\section{CONCLUSION}

Numerical results show that the MEC can further enhance the performance of the SEC. The cooling capacity generated by MEC is independent of entrainment ratio of the ejector and always higher than that of the standard cycle. Meanwhile, the cooling capacity of SEC is strongly influenced by the entrainment ratio of the ejector. The initial numerical approach shows that MEC is able to generate COP improvement much higher than SEC. As a result, further investigation on the MEC is still required.

The increase in COP improvement leads to the decrease in power consumption, consumed by the residential $\mathrm{A} / \mathrm{C}$. In addition, the experimental results show that the COP improvements of MEC are always positive with three motive nozzle diameters. The highest COP improvement when the diameter is $1.1 \mathrm{~mm}$. However, these experimental results are only valid for motive nozzle diameter between 0.9 and $1.1 \mathrm{~mm}$. Therefore, the results are not representing better COP improvement for motive nozzle diameter larger than $1.1 \mathrm{~mm}$. Thus, further extension on the experimental study with larger diameter than $1.1 \mathrm{~mm}$ is still required to provide clear picture on the effect of motive nozzle diameter to the COP improvement of the system. Consequently, the precise correlation between motive nozzle diameter and COP improvement can be drawn, and the best motive nozzle diameter to achieve the highest COP improvement can be accurately calculated.

\section{ACKNOWLEDGEMENTS}

This research was supported financially by the Minister of Research, Technology and Higher Education Indonesia with Fund No. 151.1/PL1.R7/LT/2019.

\section{NOMENCLATURE}

$\begin{array}{ll}a & \text { cross-sectional area }\left(\mathrm{m}^{2}\right) \\ \mathrm{A} / \mathrm{C} & \text { air conditioner } \\ C O P & \text { coefficient of performance } \\ h & \text { specific enthalpy }(\mathrm{kJ} / \mathrm{kg}) \\ \mathrm{MEC} & \text { modification ejector cycle } \\ P & \text { pressure }(\mathrm{kPa}) \\ Q & \text { cooling capacity }(\mathrm{kW}) \\ \mathrm{SC} & \text { standard cycle } \\ \mathrm{SEC} & \text { standard ejector cycle } \\ T & \text { temperature }\left({ }^{\circ} \mathrm{C}\right) \\ \mathrm{VCRC} & \text { vapor compression refrigeration cycle } \\ W & \text { compressor power }(\mathrm{kW}) \\ \rho & \text { density }\left(\mathrm{kg} / \mathrm{m}^{3}\right) \\ u & \text { velocity }(\mathrm{m} / \mathrm{s}) \\ U & \text { relative standard uncertainty } \\ \eta & \text { isentropic efficiency }(\%)\end{array}$


entrainment ratio

$\begin{array}{ll}\text { Subscripts } & \\ \text { cond } & \text { condenser } \\ \text { comp } & \text { compressor } \\ d b & \text { dry bulb } \\ \text { dif } & \text { diffuser } \\ \text { evap } & \text { evaporator } \\ \text { ejt } & \text { ejector } \\ \text { sn } & \text { suction nozzle } \\ m n & \text { motive nozzle } \\ w b & \text { web bulb }\end{array}$

\section{REFERENCES}

[1] Chang YS, Kim MS, Ro ST. Performance and heat transfer characteristics of hydrocarbon refrigerants in a heat pump system. International Journal of Refrigeration. 2000;23(3):232-42. doi:10.1016/s0140-7007(99)00042-0.

[2] Devotta S, Padalkar AS, Sane NK. Performance assessment of HC-290 as a drop-in substitute to HCFC-22 in a window air conditioner. International Journal of Refrigeration. 2005;28(4):594-604. doi:10.1016/j.ijrefrig.2004.09.013.

[3] Zhou G, Zhang Y. Performance of a split-type air conditioner matched with coiled adiabatic capillary tubes using HCFC22 and HC290. Applied Energy. 2010;87(5):1522-8. doi:10.1016/j.apenergy.2009.10.005.

[4] Padilla M, Revellin R, Bonjour J. Exergy analysis of R413A as replacement of R12 in a domestic refrigeration system. Energy Conversion and Management. 2010;51(11):2195-201. doi:10.1016/j.enconman.2010.03.013.

[5] Sukri MF, Musa MN, Senawi MY, Nasution H. Achieving a better energy-efficient automotive air-conditioning system: a review of potential technologies and strategies for vapor compression refrigeration cycle. Energy Efficiency. 2015;8(6):1201-29. doi:10.1007/s12053-015-9389-4.

[6] Bi S-s, Shi L, Zhang L-l. Application of nanoparticles in domestic refrigerators. Applied Thermal Engineering. 2008;28(14-15):1834-43. doi:10.1016/j.applthermaleng.2007.11.018.

[7] Xing M, Wang R, Yu J. Application of fullerene C60 nano-oil for performance enhancement of domestic refrigerator compressors. International Journal of Refrigeration. 2014;40:398-403. doi:10.1016/j.ijrefrig.2013.12.004.

[8] Bi S, Guo K, Liu Z, Wu J. Performance of a domestic refrigerator using TiO2-R600a nano-refrigerant as working fluid. Energy Conversion and Management. 2011;52(1):733-7. doi:10.1016/j.enconman.2010.07.052.

[9] Kornhauser AA. The Use of an Ejector as a Refrigerant Expander. Conference The Use of an Ejector as a Refrigerant Expander, West Lafayette, USA. p. 10-9.

[10] Li D, Groll EA. Transcritical CO2 refrigeration cycle with ejector-expansion device. International Journal of Refrigeration. 2005;28(5):766-73. doi:10.1016/j.ijrefrig.2004.10.008.

[11] Yari M, Sirousazar M. Cycle improvements to ejector-expansion transcritical CO2 two-stage refrigeration cycle. International Journal of Energy Research. 2008;32(7):677-87. doi:10.1002/er.1385.

[12] Bilir N, Ersoy HK. Performance improvement of the vapour compression refrigeration cycle by a two-phase constant area ejector. International Journal of Energy Research. 2009;33(5):469-80. doi:10.1002/er.1488.

[13] Nehdi E, Kairouani L, Bouzaina M. Performance analysis of the vapour compression cycle using ejector as an expander. International Journal of Energy Research. 2007;31(4):364-75. doi:10.1002/er.1260.

[14] Sarkar J. Geometric parameter optimization of ejector-expansion refrigeration cycle with natural refrigerants. International Journal of Energy Research. 2010;34(1):84-94. doi:10.1002/er.1558.

[15] Sumeru K, Sulaimon S, Ani FN, Nasution H. Numerical Study of an Ejector as an Expansion Device in Splittype Air Conditioners for Energy Savings. Journal of Engineering and Technological Sciences. 2013;45(2):17992. doi:10.5614/j.eng.technol.sci.2013.45.2.6.

[16] Zhou M, Wang X, Yu J. Theoretical study on a novel dual-nozzle ejector enhanced refrigeration cycle for household refrigerator-freezers. Energy Conversion and Management. 2013;73:278-84. doi:10.1016/j.enconman.2013.04.028.

[17] Hassanain M, Elgendy E, Fatouh M. Ejector expansion refrigeration system: Ejector design and performance evaluation. International Journal of Refrigeration. 2015;58:1-13. doi:10.1016/j.ijrefrig.2015.05.018. 
[18] Bilir Sag N, Ersoy HK, Hepbasli A, Halkaci HS. Energetic and exergetic comparison of basic and ejector expander refrigeration systems operating under the same external conditions and cooling capacities. Energy Conversion and Management. 2015;90:184-94. doi:10.1016/j.enconman.2014.11.023.

[19] Wang X, Yu J. An experimental investigation on a novel ejector enhanced refrigeration cycle applied in the domestic refrigerator-freezer. Energy. 2015;93:202-9. doi:10.1016/j.energy.2015.09.038.

[20] Sumeru K, Sulaimon S, Nasution H, Ani FN. Numerical and experimental study of an ejector as an expansion device in split-type air conditioner for energy savings. Energy and Buildings. 2014;79:98-105. doi:10.1016/j.enbuild.2014.04.043.

[21] Disawas S, Wongwises S. Experimental investigation on the performance of the refrigeration cycle using a twophase ejector as an expansion device. International Journal of Refrigeration. 2004;27(6):587-94. doi:10.1016/j.ijrefrig.2004.04.002.

[22] Arsana ME, Kusuma IGNW, Sucipta M, Suamir IN. Comparative Analysis of Performance between Two Phase Ejector with Accomulator and COS Split Air-Conditioning Dual Evaporator. 2018. doi:10.2991/icst18.2018.197.

[23] Banasiak K, Hafner A. 1D Computational model of a two-phase R744 ejector for expansion work recovery. International Journal of Thermal Sciences. 2011;50(11):2235-47. doi:10.1016/j.ijthermalsci.2011.06.007.

[24] Chaiwongsa P, Wongwises S. Effect of throat diameters of the ejector on the performance of the refrigeration cycle using a two-phase ejector as an expansion device. International Journal of Refrigeration. 2007;30(4):6018. doi:10.1016/j.ijrefrig.2006.11.006.

[25] Brunin O, Feidt M, Hivet B. Comparison of the working domains of some compression heat pumps and a compression-absorption heat pump. International Journal of Refrigeration. 1997;20(5):308-18. doi:10.1016/s0140-7007(97)00025-x.

[26] Taslimitaleghani S, Sorin M, Poncet S. Energy and exergy efficiencies of different configurations of the ejectorbased co2 refrigeration systems. International Journal of Energy Production and Management. 2018;3(1):22-33. doi:10.2495/eq-v3-n1-22-33.

[27] Deng J-q, Jiang P-x, Lu T, Lu W. Particular characteristics of transcritical CO2 refrigeration cycle with an ejector. Applied Thermal Engineering. 2007;27(2-3):381-8. doi:10.1016/j.applthermaleng.2006.07.016.

[28] Harrell GS, Kornhauser AA. Performance tests of a two phase ejector. Conference Performance tests of a two phase ejector, Orlando, FL vol. Volume 3. p. pp. 49-53.

[29] Menegay P, Kornhauser AA. Improvements to the ejector expansion refrigeration cycle. 1996;2:702-6. doi:10.1109/iecec.1996.553783.

[30] Elbel S, Hrnjak P. Experimental validation of a prototype ejector designed to reduce throttling losses encountered in transcritical R744 system operation. International Journal of Refrigeration. 2008;31(3):411-22. doi:10.1016/j.ijrefrig.2007.07.013.

[31] Elbel S. Historical and present developments of ejector refrigeration systems with emphasis on transcritical carbon dioxide air-conditioning applications. International Journal of Refrigeration. 2011;34(7):1545-61. doi:10.1016/j.ijrefrig.2010.11.011.

[32] Lucas C, Koehler J. Experimental investigation of the COP improvement of a refrigeration cycle by use of an ejector. International Journal of Refrigeration. 2012;35(6):1595-603. doi:10.1016/j.ijrefrig.2012.05.010.

[33] Haida M, Banasiak K, Smolka J, Hafner A, Eikevik TM. Experimental analysis of the R744 vapour compression rack equipped with the multi-ejector expansion work recovery module. International Journal of Refrigeration. 2016;64:93-107. doi:10.1016/j.jirefrig.2016.01.017.

[34] Palacz M, Smolka J, Nowak AJ, Banasiak K, Hafner A. Shape optimisation of a two-phase ejector for CO 2 refrigeration systems. International Journal of Refrigeration. 2017;74:212-23. doi:10.1016/j.ijrefrig.2016.10.013. 